\title{
Disruption of central-place foraging in the rat following lesions of the dorsomedial thalamic nucleus
}

\author{
GORDON B. SCHACTER, MARIA T. PHELPS, DAVID R. BRODBECK, \\ GORDON J. MOGENSON, and WILLIAM A. ROBERTS \\ University of Western Ontario, London, Ontario, Canada
}

\begin{abstract}
The neural basis of central-place foraging was investigated in the laboratory rat, using a sixarm radial maze. Pieces of cheddar cheese of different sizes were placed on the ends of the maze arms, and preoperative central-place foraging behavior was monitored. Then bilateral electrolytic lesions were made in the fimbria fornix (FF), amygdala (AMY), medial frontal cortex (MFC), dorsomedial thalamic nucleus (MD), and combined MFC-MD, and a comparison was made with control animals on the tendency to carry pieces of cheese to the center of the radial-arm maze. Rats with more than $77 \%$ destruction of the MD exhibited a reduction in food-carrying behavior and a concomitant increase in eating food items at the ends of arms, in comparison with control animals. Rats with less than 77\% destruction of the MD exhibited some reduction in food-carrying behavior, but they did not differ significantly from controls. Rats with lesions of the FF, AMY, and MFC did not exhibit any reduction in food-carrying behavior. These findings suggest that the MD plays a role in adaptive food-carrying behaviors that are involved in central-place foraging.
\end{abstract}

Some foraging animals do not consume food where they first encounter it. For example, wild Norway rats (Rattus norvegicus), roof rats (Rattus rattus), and gray squirrels (Sciurus carolinensis) often carry food to cover for ingestion and do not consume food in the open (Flannely, Kemble, \& Hori, 1986; Lima \& Valone, 1986; Lima, Valone, \& Caraco, 1985; Neider, Cagnin, \& Parisi, 1982). Animals that carry food to a fixed central site for feeding have been called central-place foragers (Carlson \& Moreno, 1981; Covich, 1987).

Traditional models of optimal foraging have suggested that fitness is a function of the efficiency of foraging, measured in terms of the rate of energy intake over time (E/T) (Pyke, Pulliam, \& Charnov, 1977). Recently, Lima and his co-workers have argued that the foraging behavior of animals is influenced by both $\mathrm{E} / \mathrm{T}$ and the risk of predation (Lima, 1985; Lima \& Valone, 1986; Lima et al., 1985). Carrying food to cover ensures that an animal will not be exposed to predation during food consumption, but carrying all food items expends too much time and energy. Foraging animals can trade off $\mathrm{E} / \mathrm{T}$ against the risk of predation by carrying large items to safety and consuming small items where they are found. Because small items can be consumed rapidly, the risk of predation or food theft is minimal.

We thank Bruce Arpe for preparing the illustrations. This study is funded by grants from the Natural Science and Engineering Research Council of Canada to G. J. Mogenson and W. A. Roberts. All correspondence concerning this article should be addressed to William A. Roberts, Department of Psychology, University of Western Ontario, London, Ontario N6A 5C2, Canada.
It has been shown in gray squirrels that as the size of a food item increases, the probability of carrying the item to cover increases. Furthermore, as the distance of a food item from cover increases, the probability of carrying the item to cover decreases (Lima \& Valone, 1986; Lima et al., 1985). As the round-trip time between the food patch and the central place exceeds the time required to consume food, the optimal strategy is to eat all the items in the patch.

Recently, it has been shown that a number of the centralplace foraging strategies seen in wild rodents can be demonstrated in laboratory rats on the radial maze (Phelps \& Roberts, 1989). Food items consisting of pieces of cheese varying in weight and size were placed on the ends of the arms of a four-arm radial maze. Rats allowed to forage among the arms (patches) ate small food items on the arms but increasingly tended to carry items to the center of the maze for consumption as item size increased. Similar findings have been observed by Whishaw and Tomie (1989). Phelps and Roberts (1989) also measured the time that rats took to complete different components of foraging and found several phenomena that agree with observations of gray squirrels in the wild. Rats on the radial maze ate food more rapidly on the arms than in the center. Further, rats, like gray squirrels, move more quickly when carrying food to the center of the maze than when traveling out on an arm in search of food or returning to the center without food. In further experiments, the structure of the radial maze has been varied, and it has been shown that rats carrying food are attracted to the center of the maze and to other places where a number of branches or escape routes are available (Phelps \& Roberts, 1989; Roberts, Phelps, \& Schacter, in press). 
A number of lines of converging evidence, then, suggest that innate foraging strategies are used by laboratory rats on the radial maze. Central-place foraging on the maze appears to be guided by genetically programmed decision-making processes (Roberts, in press). As further support for this suggestion, it has been observed that food carrying on the maze appears on the 1st day of experimentation in naive rats and persists with little modification through as many as $\mathbf{5 0}$ days of testing (Phelps \& Roberts, 1989).

In the present study, the neural mechanisms of centralplace foraging were investigated in the laboratory rat by observing the effects of electrolytic brain lesions on radialmaze foraging. Food items of different sizes were placed on the arms of a six-arm radial maze, and rats were given preoperative experience on the maze to establish baseline performance of food-carrying behavior. Lesions were then made in the fimbria fornix (FF), a major extrinsic fiber connection of the hippocampus; amygdala (AMY); medial frontal cortex (MFC), including the prelimbic and infralimbic sectors of the prefrontal cortex; dorsomedial thalamic nucleus (MD); and combined MFC-MD. Postoperative food-carrying behavior was then observed in these lesioned rats and in control animals with either sham lesions or no lesions. The neural structures that were lesioned were chosen by examining the behavioral components of central-place foraging, and by reviewing evidence in the literature for possible neural bases of these components.

Central-place foraging consists of a number of goaldirected locomotor responses. Animals engage in locomotion when they search for food patches, search within a food patch, carry food items, and escape from predators. The hippocampus and its extrinsic fiber connections are neural structures that contribute to goal-directed locomotion, and thus they may play a role in central-place foraging (Flicker \& Geyer, 1982; Isaacson, 1982; Mogenson \& Neilsen, 1984; Yang \& Mogenson, 1987).

Central-place foraging clearly involves consummatory behaviors, such as food handling and ingestion. Because the AMY is a neural structure that contributes to consummatory behavior, it may play a role in central-place foraging (Box \& Mogenson, 1975; Chozick, 1986; Fonberg, 1981; Rolls \& Rolls, 1973; Vergnes, 1981).

A major characteristic of central-place foraging is food carrying. Research into the neural bases of food carrying has focused on the area of food hoarding. Neural structures important for food hoarding that may play a role 'in food-carrying behavior are the MD (Kolb, 1977; Mogenson \& Wu, 1988) and the MFC, including the prelimbic and infralimbic sectors of the prefrontal cortex (Kolb, 1977; Stamm, 1953; Whishaw \& Oddie, 1989).

Central-place foraging also involves visuospatial information processing. Animals must be able to (1) locate and remember the location of food patches; (2) locate areas where food will be carried that are safe from predation; and (3) process perceptual information about a food item in order to decide whether the item should be carried to a safer place for consumption. Neural structures involved in visuospatial information processing include the hippocampus and its extrinsic fiber connections ( $\mathrm{O}^{\prime}$ Keefe \& Dostrovsky, 1971; Olton, Branch, \& Best, 1978; Olton, Walker, \& Gage, 1978; Olton, Walker, \& Wolf, 1982), the MFC (Kolb, Pittman, Sutherland, \& Whishaw, 1982), and the MD (Kessler, Markowitsch, \& Otto, 1982; Stokes, 1988; Stokes \& Best, 1988).

One of the major conditions that govern central-place foraging is antipredatory behavior. Neural structures that contribute to the emotional reactions of aggression and fear are located in the AMY (Mogenson, 1987; Vergnes, 1981) and the MD (Bandler, 1971; Markowitsch, 1982; Waring \& Means, 1976) and may be involved in the antipredatory behavior of central-place foraging.

\section{METHOD}

\section{Subjects}

Sixty-one male Long-Evans hooded rats (Rattus norvegicus) weighing $250-300 \mathrm{~g}$ at the start of the experiment were used as subjects. They were housed individually in wire mesh cages and were exposed to a 16:8-h light:dark schedule. The onset of the light occurred at 6:00 a.m.; the offset, at 10:00 p.m. The animals were kept at approximately $85 \%$ of their free-feeding weight for preoperative training and postoperative testing and were raised to $95 \%$ of their free-feeding weight prior to surgery. Water was available throughout the experiment ad lib. Training and testing were conducted between the hours of 10:00 a.m. and 5:00 p.m.

\section{Apparatus}

The open, elevated six-arm radial maze was constructed of plywood and painted black. The six arms radiated from a circular central platform, with a $60^{\circ}$ angle between adjacent arms. The central platform was $36 \mathrm{~cm}$ in diameter, and each arm was $72 \mathrm{~cm}$ long and $9 \mathrm{~cm}$ wide. The maze was located in a $2.1 \times 3.1 \mathrm{~m}$ room illuminated by two enclosed, overhead fluorescent light units. A blind made of black poster board mounted on a wooden frame, measuring $111 \mathrm{~cm}$ wide by $145 \mathrm{~cm}$ high, was placed adjacent to the maze. The experimenter sat behind the blind, observed the subjects' behavior through a small hole in the blind, and recorded the subjects' behavior by entering appropriate behavioral codes into a Commodore 64 computer. White noise was played through an overhead speaker throughout the experiment.

\section{Preliminary Training}

The rats were placed on a deprivation schedule 5 days prior to preoperative training. They were weighed and handled daily and were adapted to the experimental food (Kraft's American processed cheese) in their home cages.

Prior to preoperative training, the rats were given preliminary training on the maze for 3-5 days. Small pieces of cheese $(0.05 \mathrm{~g})$ were placed on the ends of the maze arms. Each rat was placed on the central platform of the maze and allowed to explore the maze freely and eat the pieces of cheese. Once the rats were running reliably down the arms of the maze and consuming the food located there, preliminary training was concluded.

\section{Preoperative Training}

In an initial small study, 9 rats were trained for 5 days. In a subsequent larger study, 52 rats were trained for 10 days. Food items consisted of cubes of mild cheddar cheese that weighed $0.05,0.45$, $0.90,1.80$, and $2.70 \mathrm{~g}$. At the beginning of a trial, five of the six arms of the maze were baited with cheese. The arms of the maze 
were labeled A, B, C, D, E, and F. The assignment of item sizes to arms was varied between rats, but for individual rats the assignment was held constant across trials. Each rat was placed on the central platform of the maze, and then the experimenter stepped behind the blind. Separate codes were entered into the computer to indicate a rat's response to food items. A printout from the computer provided a record of the arms entered and the behavior exhibited. The responses of major interest were eat on arm, carry to center, and eat in center. For a response to qualify as a carry, a rat had to carry the food item back to the central platform of the maze before consumption. If the subject consumed the item where it was located, this was labeled eating on the arm.

\section{Surgery}

The rats were anesthetized with sodium pentobarbital (Somnotol, $60 \mathrm{mg} / \mathrm{kg}$, i.p.) and positioned in a Kopf stereotaxic apparatus. The stereotaxic coordinates used were obtained from a standard atlas of the rat brain (Pellegrino, Pellegrino, \& Cushman, 1979), with the incisor bar adjusted $5 \mathrm{~mm}$ above the interaural plane. The rats were given bilateral electrolytic lesions of the MFC (A-P $=3.4$, 4.0 , and $4.6 \mathrm{~mm}, \mathrm{~L}-\mathrm{M}=0.8 \mathrm{~mm}, \mathrm{D}-\mathrm{V}=2.5$ and $3.5 \mathrm{~mm}), \mathrm{MD}$ (A-P $=-1.4 \mathrm{~mm}, \mathrm{~L}-\mathrm{M}=0.9 \mathrm{~mm}, \mathrm{D}-\mathrm{V}=5.4 \mathrm{~mm}), \mathrm{AMY}(\mathrm{A}-\mathrm{P}$ $=-1.0 \mathrm{~mm}, \mathrm{~L}-\mathrm{M}=5.0 \mathrm{~mm}, \mathrm{D}-\mathrm{V}=8.0 \mathrm{~mm}), \mathrm{FF}(\mathrm{A}-\mathrm{P}=$ $-0.2 \mathrm{~mm}, \mathrm{~L}-\mathrm{M}=1.0 \mathrm{~mm}, \mathrm{D}-\mathrm{V}=3.5 \mathrm{~mm}$ ), and combined $\mathrm{MFC}$ and MD. All lesions were made by passing a direct anodal current of 1.0-2.0 mA for 15-25 sec through a stainless steel wire that was insulated except for about $0.5 \mathrm{~mm}$ at the tip. For sham lesions, the electrode was lowered into the brain without penetration of target areas, and current was not passed through the electrode. Upon completion of surgery, rats were given an antibiotic to prevent infection (Pen-Di-Strep, $50 \mathrm{mg} / \mathrm{kg}$ i.m.) and allowed to recover for $5-7$ days. During postsurgical recovery, the rats were handled for 5-10 min daily.

\section{Postoperative Testing}

All animals were tested postoperatively with the same procedure that was used in preoperative training. The 9 rats given 5 days of preoperative training were tested for 5 days postoperatively, and the 52 rats trained for 10 days preoperatively were tested for 10 days postoperatively. Among the rats tested for 5 days, 2 were in the MFC lesion group, 2 were in the FF lesions group, 2 were in the MD lesion group, and 3 were in the combined MFC and MD lesion group.

\section{Histology}

Following completion of the experiment, the rats were sacrificed by an overdose of sodium pentobarbitol (Somnotol) and perfused transcardially with $50 \mathrm{ml}$ of $0.9 \% \mathrm{NaCl}$ followed by $50 \mathrm{ml}$ of buffered formalin. Their brains were then removed from the skull and fixed in formalin for a minimum of $24 \mathrm{~h}$. They were then sectioned at $80 \mu \mathrm{m}$, using a freezing microtome and stained with thionin for histological determination of lesion sites.

In the animals with destruction of the $\mathrm{MD}$, lesions were examined by means of a grid system analysis. Brain sections corresponding to selected plates of the Pellegrino et al. (1979) stereotaxic atlas of the rat brain were projected onto gridded copies of these plates, using a projecting microscope. The projecting microscope was set at $12 \mathrm{X}$ magnification, which corresponded to the magnification level of the plates. Eight gridded plates were used, ranging from $0.6 \mathrm{~mm}$ posterior to bregma to $2.0 \mathrm{~mm}$ posterior to bregma at $0.2-\mathrm{mm}$ intervals. Each grid was composed of $0.3 \times 0.3 \mathrm{~mm}$ squares. The locus and the extent of damage were reproduced by referring to standard landmarks on each section, such as the fimbria, hippocampus, and mamillothalamic tract. The area of evacuation and gliosis defined the damage. The number of grids that was within the area of damage was compared to the total number of grids within the MD of each atlas plate. Thus, a percent damage of the MD was calculated. In the case of asymmetrically cut sections or sections that did not correspond precisely to a given atlas plate, precise reproduction of lesion damage was obtained by means of careful interpolation with one or more anterior and posterior sections.

\section{Data Analysis}

To facilitate a statistical comparison, the frequency with which food items were carried to the center of the maze or consumed on the end of the maze arms was converted to a percentage. Percentage of items carried and percentage of items consumed on an arm were complementary measures; therefore, the data have been reported only as percentage carried to the center of the maze. Five subjects were dropped from pre- and postoperative statistical analyses, because lesions did not destroy any of the target areas. Two subjects were dropped from further analyses because they did not exhibit food-carrying behavior preoperatively at the largest fooditem weight of $2.70 \mathrm{~g}$. Therefore, the animals that were used for statistical analyses were as follows: unoperated control $(n=7)$, sham control $(n=11)$, MFC lesion group $(n=11)$, MD lesion group $(n=6)$, AMY lesion group $(n=6)$, FF lesion group $(n=7)$, and combined MFC and MD lesion group $(n=6)$.

Separate repeated measures analyses (ANOVAs) were performed on the percentages of items carried to the center of the maze. The factors in all subsequent analyses were item size and group assignment. All statistical tests were considered significant if $p<.05$.

\section{RESULTS}

\section{Preoperative Performance}

Within the group of 45 rats tested for 10 days, there was a small but significant increase in the tendency to carry large food items to the center between Days 1-5 and $6-10[F(4,44)=4.88]$. However, the 9 rats tested for 5 days did not differ in food-carrying frequency from the 10-day rats on either Days 1-5 $[F(1,52)=2.06]$ or Days 6-10 $[F(1,52)=0.58]$. Therefore, the two groups of rats were combined for all subsequent analyses.

Item weight $\times$ postoperative treatment group ANOVAs were performed on the percentage of items carried to the center of the maze. There was an increasing tendency to carry food items as item weight increased $[F(4,188)=$ 214.77]. There was no significant difference between groups $[F(6,47)=0.53]$, nor was there a significant interaction of group $\times$ item weight $[F(24,188)=1.06]$. For the purpose of illustration, the percentages of items carried to the center by the six to-be-lesioned groups were combined and are shown for each item weight in Figure 1.

\section{Postoperative Performance}

The 45 animals tested for 10 days postoperatively performed at the same level throughout the 10 days. No significant differences in food-carrying frequency were found between Days 1-5 and 6-10 for any of the lesion or control groups. Each of the 9 animals tested for 5 days was comparable to the animals in its respective lesion group, and therefore data from the 5-day and 10-day animals were combined in each group for all subsequent analyses.

An ANOVA was performed on the percentage of items carried to the center of the maze by the unoperated and sham-lesioned animals. The tendency to carry food items increased with increasing food-item weight $[F(4,63)=$ 


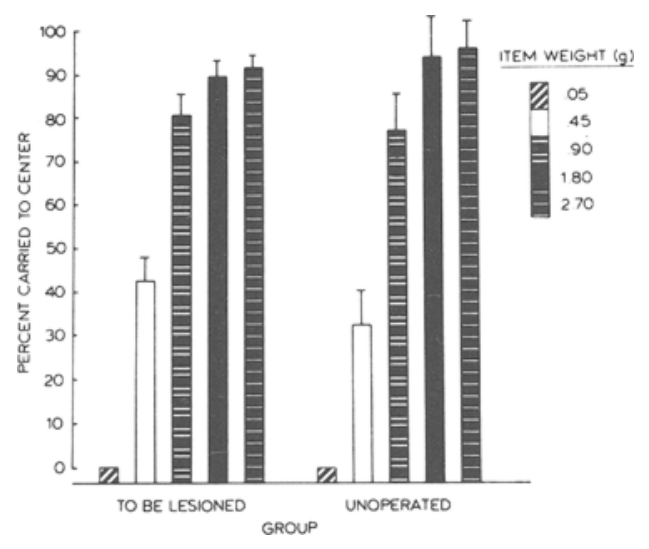

Figure 1. Percentage of items carried to the center of the maze during preoperative training, shown for each item weight. Separate bars and SEMs are shown for the unoperated and to-be-lesioned animals.

71.37], but there was no significant effect of group $[F(1,16)=0.29]$ and no significant interaction of group $X$ item weight $[F(4,63)=1.32]$. The results for the unoperated and sham-lesioned animals were combined, and this group will hereafter be referred to as the control group $(n=18)$. The control group served as a baseline against which lesioned groups were statistically compared.

Bilateral electrolytic lesions of the MFC, AMY, and FF had no effect on food-carrying behavior. Lesions of the MD and MD-MFC did lead to a lower level of food carrying than that observed in the control group, but the $M D$ and MD-MFC groups did not differ significantly from the control group. An examination of the behavior of individual animals within both the MD and the MD-MFC groups showed a clear bimodal distribution, with some animals carrying large food items on almost all occasions and some animals showing little tendency to carry large food items. On the basis of this observation, damage to the MD in the MD and MD-MFC lesion groups was analyzed, using a grid system. Grid system analysis revealed variability in the amount of destruction to the MD. Animals were then ranked according to the percentage destruction of the MD, with a median of $77 \%$ destruction. Animals with less than $77 \%$ destruction of the $\mathrm{MD}(n=6)$ formed one group, and animals with more than $77 \%$ destruction to the MD $(n=6)$ formed another group. Three rats from the MD-MFC lesion group and 3 rats from the MD group had more than $77 \%$ destruction of the MD, and the other 3 rats in each group had less than $77 \%$ destruction of the MD. Among rats in the MD-MFC group, there was little difference in the extent of MFC damage between the two subgroups with more than and less than $77 \%$ destruction of the MD.

The percentage of items carried to the center of the radial-arm maze are shown as a function of item weight in Figure 2. Separate sets of bars for different item weights are presented for the control, AMY, FF, MFC, MD less than $77 \%$, and MD more than $77 \%$ groups.

Lesions in the MD less than $77 \%$ group were bilateral but generally small, often including the habenular nucleus and stria medullaris, as can be seen in Figure 3. Damage to nuclei other than the MD were not correlated with behavioral changes. As is shown in Figure 2, rats in the MD less than $77 \%$ group did exhibit some decrease in food carrying. However, an ANOVA indicated that these animals did not differ significantly from control animals in the tendency to carry food items to the center of the maze for consumption $[F(1,22)=0.04]$, and there was no significant interaction of group $\times$ item weight $[F(4,88)$ $=2.14]$. Item weight exerted a significant effect on the likelihood that a food item would be carried $[F(4,88)=$ 46.84].

Lesions in the MD more than $77 \%$ group were bilateral and large, including all or most of the MD nucleus, as can be seen in Figure 4. In 2 animals, lesions extended anterior to the MD and included the anteromedial nucleus of the thalamus, and in 1 animal, lesions extended posterior to the MD and included the parafascicular nucleus. For the most part, lesions extended to other midline nuclei, including the habenular, paraventricular, paratenial, rhomboid, and reuniens nuclei and the stria medullaris. In the case of the largest lesion, damage extended to the dentate gyrus of the hippocampus. In 2 animals, lesions were fairly circumscribed and included most of the MD nucleus, but spared the habenular nucleus and the stria medullaris. In one of these cases, the reuniens nucleus was also spared.

As shown in Figure 2, there was a decrease in foodcarrying behavior by the MD more than $77 \%$ group relative to control animals. The most dramatic difference was observed at the item weight of $2.70 \mathrm{~g}$. The $2.70-\mathrm{g}$ item was carried to the center $95 \%$ of the time by control animals and $18 \%$ of the time by animals in the MD more than $77 \%$ group. An ANOVA indicated that animals with more than $77 \%$ destruction to the MD differed significantly from control animals $[F(1,22)=10.95]$. There was a significant effect of item weight on the tendency to carry food items to the center $[F(4,88)=27.84]$. A significant

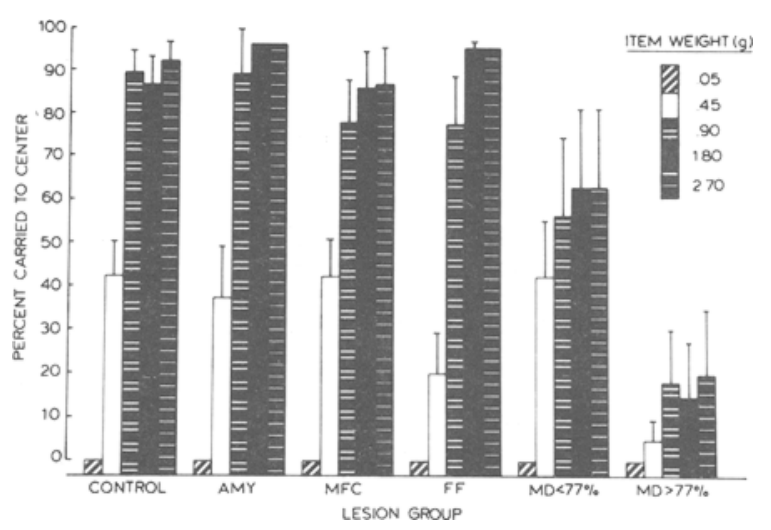

Figure 2. Percentage of items carried to the center of the maze during postoperative testing, shown for each item weight. Separate bars and SEMs are shown for the control, AMY, FF, MFC, MD less than 77\%, and MD more than 77\% groups. AMY = amygdala; FF = fimbria fornix; MFC = medial frontal cortex; and MD = dorsomedial thalamic nucleus. 

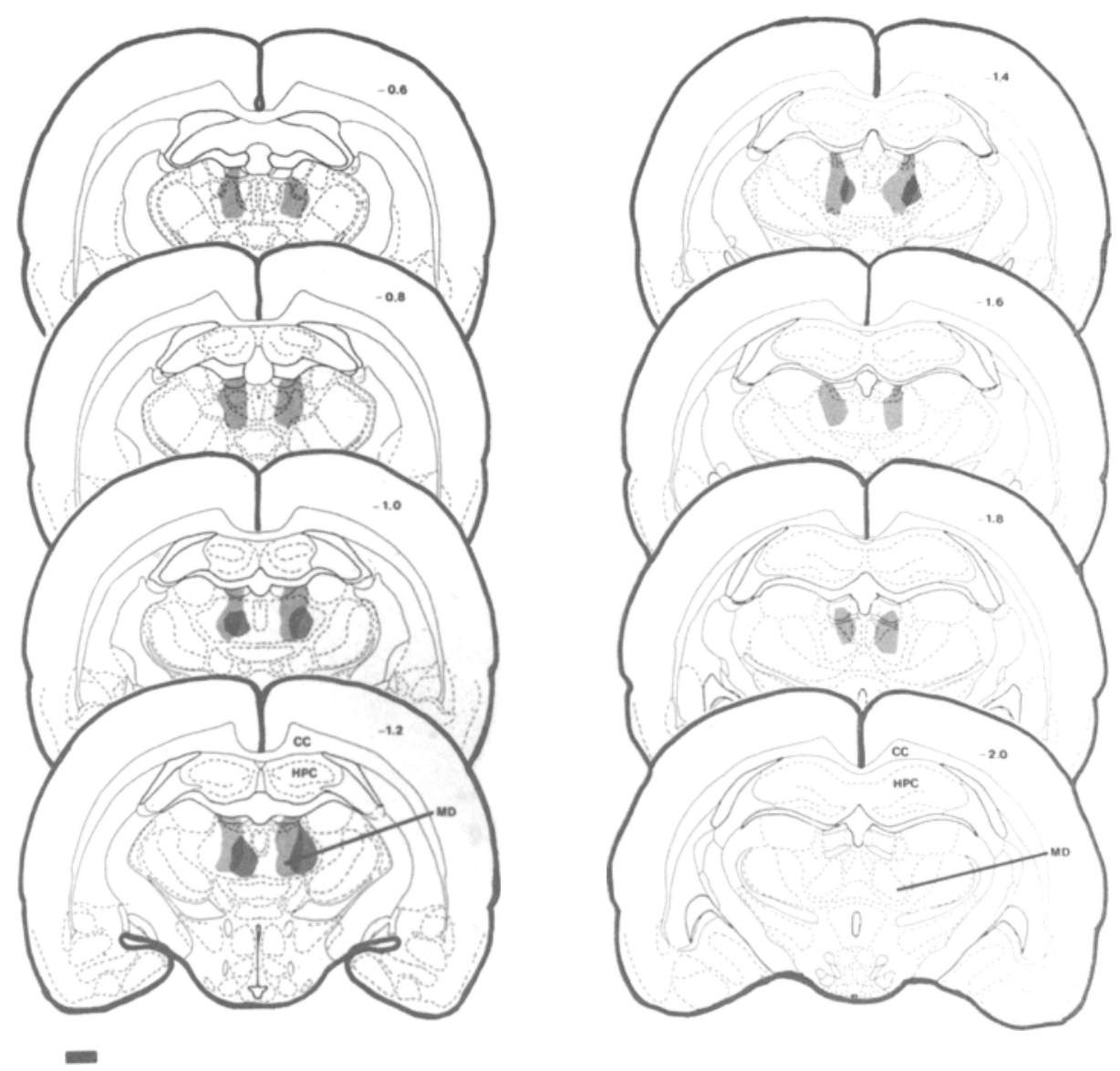

Figure 3. Diagrammatic representations of electrolytic lesions of the MD, in the less than $77 \%$ group, shown on coronal sections of the rat brain. Light shading indicates the largest lesion, and dark shading represents the smallest lesion. Numbers represent the distance posterior to bregma (0.0). Bar $=1 \mathrm{~mm}$. $\mathrm{CC}=$ corpus callosum; HPC = hippocampus; $\mathrm{MD}=$ dorsomedial thalamic nucleus.

interaction of group $\times$ item weight was found $[F(4,88)$ $=12.49]$. The presence of this interaction reflects the tendency of the MD more than $77 \%$ group to carry progressively fewer food items to the center of the maze than the control group did, as food size increased.

A repeated measures ANOVA was performed on the percentage of items carried to the center, with the factors being MD more than $77 \%$ versus MD less than $77 \%$ groups, and item weight. There was a significant effect of item weight on food-carrying behavior $[F(4,40)=$ 8.32]. Although there was no significant effect of group $[F(1,10)=3.86]$, a significant interaction of group $\times$ item weight was found $[F(4,40)=2.81]$, which is indicative of the fact that neither group carried the $0.05-\mathrm{g}$ items but that the less than $77 \%$ group carried more items than did the more than $77 \%$ group, at large item sizes. The mean percentage of items carried for each item weight by MD more than $77 \%$ and MD less than $77 \%$ groups were compared statistically, using one-tailed $t$ tests. Food was carried significantly less frequently by the MD more than $77 \%$ group than by the MD less than $77 \%$ group at the item weights of $0.45 \mathrm{~g}[t(10)=2.29], 1.80 \mathrm{~g}[t(10)$
$=2.01]$, and $2.70 \mathrm{~g}[t(10)=1.81]$. Only at the item weight of $0.90 \mathrm{~g}$ was a significant effect not observed $[t(10)=1.63]$.

Lesions of the FF were placed anterior to the hippocampus and posterior to the septal nuclei, as can be seen in Figure 5. In 4 of the 7 animals, lesions destroyed the medial portions of the FF, with sparing of the lateral tips. In the remaining 3 animals, lesions destroyed both medial and lateral portions of the FF. An ANOVA revealed that food-item size had a significant effect on the likelihood that food items would be carried to the center of the maze for consumption $[F(4,92)=104.55]$ in FF-lesioned animals. However, FF-lesioned animals did not differ significantly from controls $[F(1,23)=0.03]$, and there was no significant interaction of group $\times$ item weight $[F(4,92)$ $=1.83$ ].

Lesions of the AMY were placed in the basal lateral and basal medial nuclei, as can be seen in Figure 6. An ANOVA revealed that item weight had a significant effect on the likelihood that food items would be carried to the center of the maze for consumption $[F(4,88)=$ 84.74] in AMY-lesioned animals. However, AMY- 

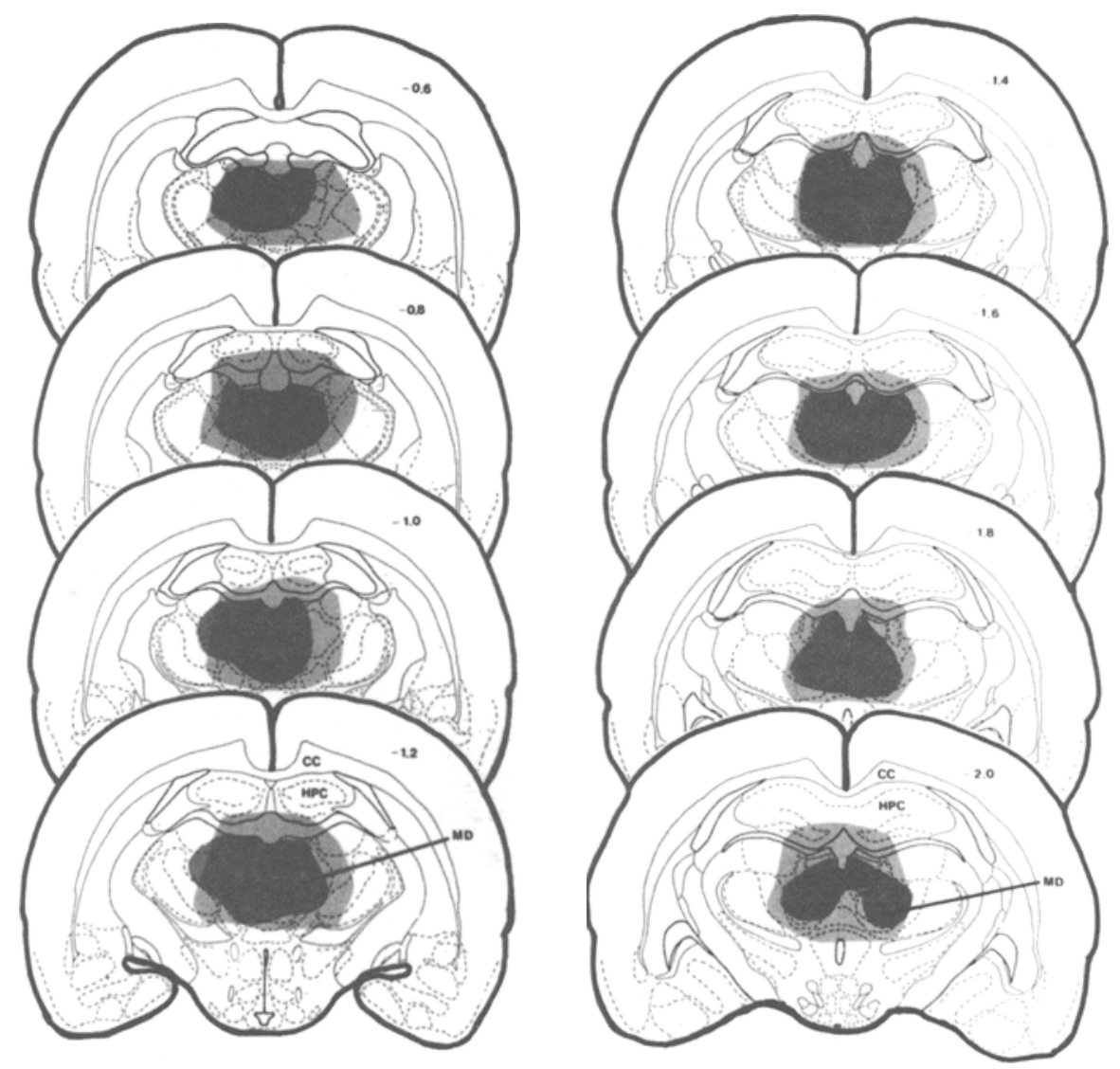

Figure 4. Diagrammatic representations of electrolytic lesions of the $\mathrm{MD}$, in the more than $77 \%$ group, shown on coronal sections of the rat brain. Light shading indicates the largest lesion, and dark shading represents the smallest lesion. Numbers represent the distance posterior to bregma (0.0). Bar = $1 \mathrm{~mm}$. CC = corpus callosum; HPC = hippocampus; $\mathrm{MD}=$ dorsomedial thalamic nucleus.

lesioned animals did not differ significantly from controls $[F(1,22)=0.24]$, and there was no significant interaction of group $\times$ item weight $[F(4,88)=0.56]$.

Lesions of the MFC were bilateral, with damage that included most of the prelimbic and infralimbic sectors of the prefrontal cortex, as can be seen in Figure 7. In 6 animals, lesions were restricted to the prelimbic and infralimbic sectors of the prefrontal cortex. In another 5 animals, damage extended rostrally throughout the MFC. There was no damage to the caudate putamen or the septal nuclei in any animal. Behavioral observations were confirmed statistically in that only item weight exerted a significant effect on the tendency to carry food items to the center of the maze for consumption $[F(4,108)=120.55]$ in MFC-lesioned animals. There was no significant difference between the control and MFClesioned groups $[F(1,27)=0.15]$, and there was no significant interaction of group $\times$ item weight $[F(4,108)$ $=0.49$ ].

\section{DISCUSSION}

Bilateral electrolytic lesions of the MD reduced foodcarrying behavior with a concomitant increase in the eating of food items at the ends of arms of a radial-arm maze. These effects were statistically significant when $77 \%$ or more of the MD was damaged. Bilateral electrolytic lesions of the MFC, FF, and AMY did not influence the measures of central-place foraging behavior.

Although lesions of the MD produced a reduction in food-carrying behavior, some MD-lesioned animals still showed food-carrying behavior on occasion. When these rats carried food, they displayed the characteristic sequence of behaviors that included securing the food item between the teeth, pivoting, and then darting back to the center of the maze at a more rapid rate than that at which the arm was entered (Phelps \& Roberts, 1989). Together, these observations suggest that the MD itself may not function to elicit the characteristic sequence of behaviors 


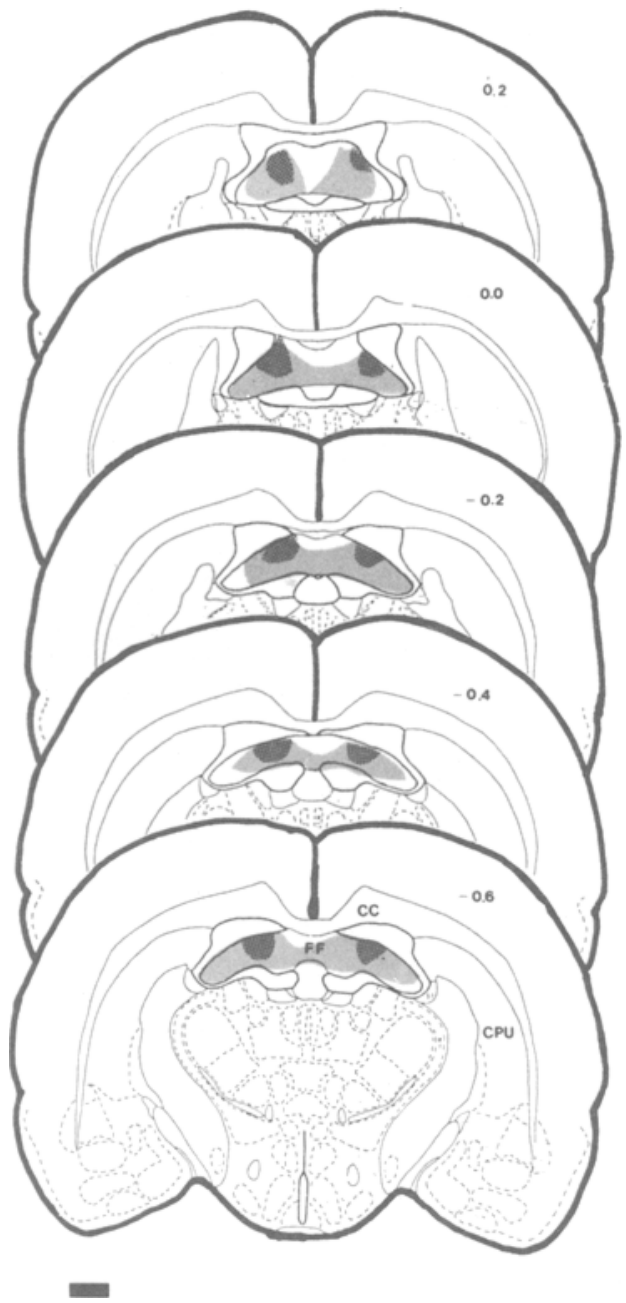

Figure 5. Diagrammatic representations of electrolytic lesions of the FF shown on corougl sections of the rat brain. Light shading indicates the largest lesions, and dark shading represents the smallest lesion. Numbers represent the distance anterior and posterior to bregma (0.0). Bar $=1 \mathrm{~mm} . \mathrm{CC}=$ corpus callosum; $\mathrm{CPU}=$ caudate putamen; $F F=$ fimbria fornix.

involved in food carrying, but may be involved in the decision-making processes of whether or not to carry food items. It has been suggested that animals with lesions of the MD fail to elicit appropriate behavioral responses to fear-arousing stimuli (Vanderwolf, 1971; Waring \& Means, 1976). Furthermore, Stokes (1988) suggested that the MD may be involved in assigning emotional value to sensory and associative information and directing responses to appropriate motor systems. Thus, in the present study, rats with MD lesions may have been impaired at evaluating the predation risk of environments, or at evaluating the value of food items that were encountered when foraging. If so, rats with MD lesions would be expected to have made maladaptive behavioral responses during central-place foraging.

The prefrontal cortex (PFC) receives strong afferent projections from the $M D$, and in turn the PFC sends a strong efferent projection to the MD (Groenewegen, 1988; Krettek \& Price, 1977; Leonard, 1969). The presence of these strong reciprocal connections has led to speculation that the functions of these two structures may be similar. Behavioral evidence supporting this speculation comes from the observation that disruptions of the PFC and MD produce similar reductions in the hoarding behavior of rats (Kolb, 1974, 1977; Mogenson \& Wu, 1988; Stamm, 1953; Whishaw \& Oddie, 1989). In the present experiment, lesions of the MD produced a reduction in the foodcarrying behavior of rats. However, lesions of the MFC that included destruction of the PFC did not alter foodcarrying behavior.

The observations that lesions of the PFC reduced hoarding behavior (Kolb, 1974, 1977; Mogenson \& Wu, 1988; Stamm, 1953; Whishaw \& Oddie, 1989) but had no ef-

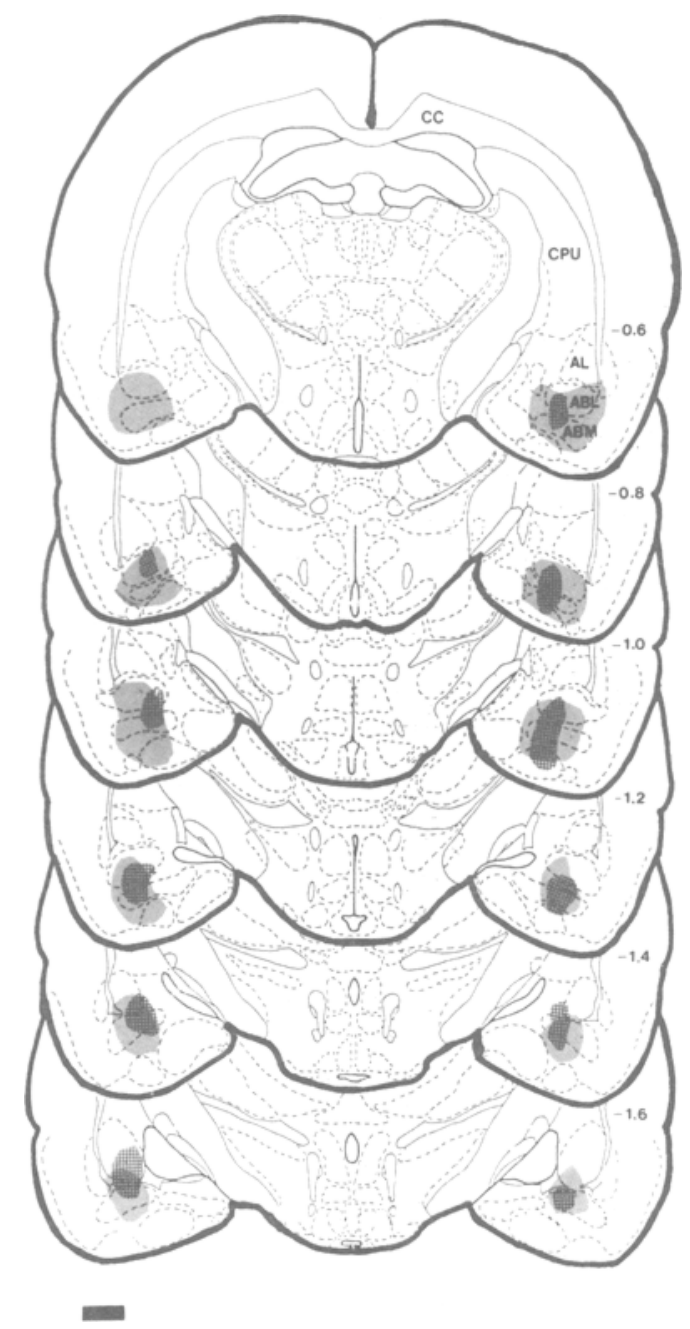

Figure 6. Diagrammatic representations of electrolytic lesions of the amygdala (AMY), shown on coronal sections of the rat brain. Light shading indicates the largest lesion, and dark shading represents the smallest Jesion. Numbers represent the distance posterior to bregma (0.0). Bar $=1 \mathrm{~mm} . \mathrm{ABL}=$ basal lateral amygdala; $\mathbf{A B M}=$ hasal medial amygdala; $A L=$ lateral amygdala; $\mathbf{C C}$ = corpus callosum; $\mathbf{C P U}=$ caudate putamen. 


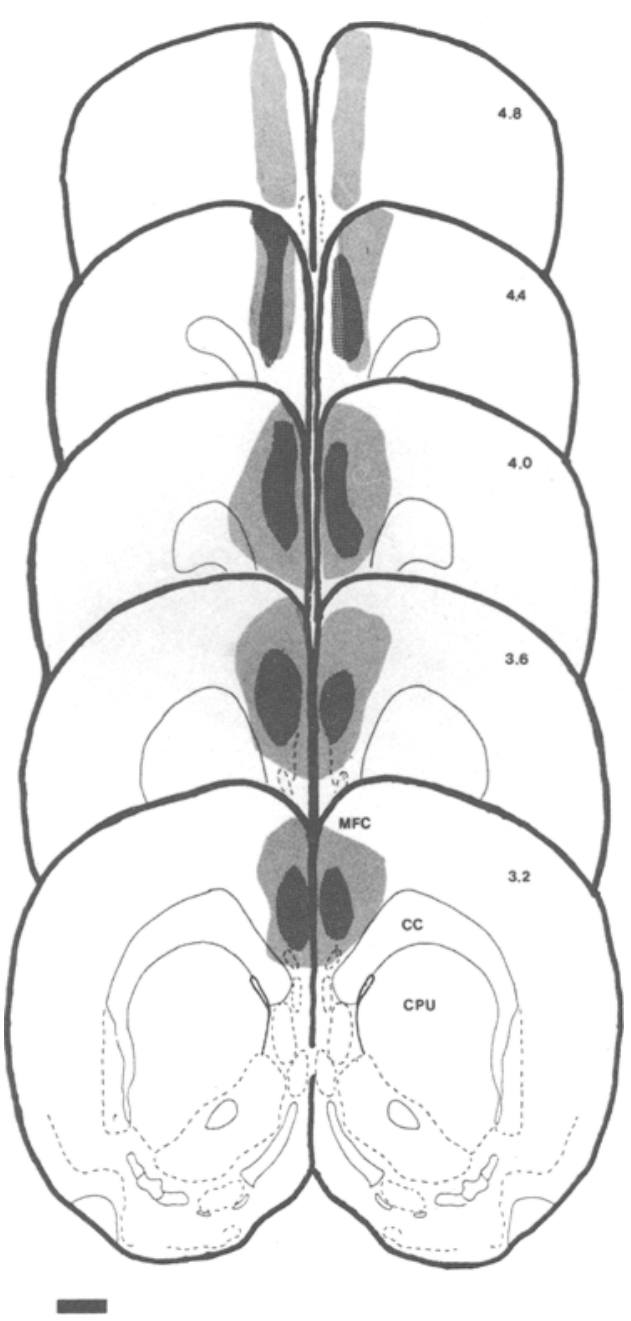

Figure 7. Diagrammatic representations of electrolytic lesions of the MFC, shown on coronal sections of the rat brain. Light shading indicates the largest lesion, and dark shading represents the smallest lesion. Numbers represent the distance anterior to bregma (0.0). Bar $=1 \mathrm{~mm} . \mathrm{CC}=$ corpus callosum; $\mathrm{CPU}=$ caudate putamen; MFC = medial frontal cortex.

fect on food-carrying behavior appear contrasting. However, these observations may be explained on the basis that hoarding behavior and central-place foraging foodcarrying behavior differ from a behavioral and ethological perspective (Covich, 1987). Food-hoarding behavior in laboratory rats consists of a rat's exiting a cage onto a runway, securing a food item between its teeth, carrying it to some particular spot in the cage for deposit, and then repeating the act without consuming any of the food (Wolfe, 1939). It is the deferment of consumption of a food item that distinguishes hoarding from other types of foraging behavior (Vander Wall \& Smith, 1987). The function of hoarding is to acquire a disproportionate share of an abundant short-lived resource (Clarkson, Eden, Sutherland, \& Houston, 1986; Covich, 1987). Phelps and Roberts (1989, Experiment 2) found that item size dissociated hoarding from central-place foraging. It was found that rats hoarded only the larger food items but carried intermediate-sized items to the center for immediate consumption. The decision to store food during periods of increased abundance functions to reduce the risk of food deprivation over time and to protect these resources from consumption by others (Covich, 1987). It also permits the animals to feed on these stored resources without risking exposure to predation. Central-place foraging foodcarrying behavior on the radial-arm maze consists of a rat's running out onto an alley from the center of the maze, securing a food item between its teeth, and carrying it back to the center of the maze for immediate consumption. The function of food-carrying behavior in centralplace foragers is to reduce the risk of predation. Therefore, central-place foraging food-carrying behavior primarily differs from food hoarding in that there is no deferment of food consumption and that the risk of predation during the eating of food items is the factor that controls the decision to carry food items. Hence, it is possible that different neural mechanisms may control centralplace foraging food-carrying behavior and food-hoarding behavior.

A second reason for the lack of reduction in foodcarrying behavior observed after lesions of the PFC in the present experiment may be differences in lesion size and technique. For example, Whishaw and Oddie (1989) found that rats will tend to hoard only large food items and that aspiration of the MFC reduces this hoarding behavior. In the present investigation, MFC lesions were electrolytic, with some animals having damage restricted to the prelimbic and infralimbic sectors of the PFC. Thus it is possible that only lesions of the entire medial frontal pole will affect central-place foraging food-carrying behavior.

The function of food-carrying behavior in central-place foragers is to allow animals to trade off foraging efficiency with predation risk (Lima, 1985; Lima \& Valone, 1986; Lima et al., 1985). In the present experiment, it has been demonstrated that rats with lesions of the MD perform maladaptive behavioral responses when central-place foraging on a radial-arm maze. The reduction in foodcarrying behavior observed after MD lesions suggests that the animals were no longer foraging in a manner that traded off energy intake with predation risk. Such behavior in the wild would expose the animal to a higher risk of predation, which in turn could lead to reduced fitness and even death. The present investigation, to our knowledge, is the first in which the neural basis of central-place foraging behavior has been examined. There are numerous recent ethological studies of adaptive foraging behaviors by animals both in the wild and in the laboratory. Further investigations similar to the present study should begin to reveal the neural basis of foraging behavior.

\section{REFERENCES}

BANDLER, R. J. (1971). Direct chemical stimulation of the thalamus: Effects on aggressive behavior in the rat. Brain Research, 26, 81-93. Box, B. M., Mogenson, G. J. (1975). Alterations in ingestive be- 
haviors after bilateral lesions of the amygdala in the rat. Physiology \& Behavior, 15, 679-688.

Cartson, A., Moreno, J. (1981). Central place foraging in the wheatear Oenanthe: An experimental test. Journal of Animal Ecology, 50, 917-924.

Chozick, B. S. (1986). The behavioral effects of lesions of the amygdala: A review. International Journal of Neuroscience, 29, 205-221.

Clarkson, K., Eden, S. F., Sutherland, W. J., a Houston, A. I. (1986). Density-dependence and magpie food-hoarding. Journal of Animal Ecology, 55, 111-121.

Covich, A. P. (1987). Optimal use of space by central place foragers: When and where to store surplus resources. In L. Green \& H. Kagel (Eds.), Advances in behavioral economics (pp. 249-294). Norwood, NJ: Ablex.

Flannely, K. J., Kemble, E. D., \& Horı, K. (1986). Structure, contents and distribution of roof rat (Raths ramus) burrows in a rain forest. Journal of Comparative Psychology, 100, 208-214.

Flicker, C., Geyer, M. A. (1982). Behavior during hippocampal microinfusion: II. Muscarinic locomotor activation. Brain Research Reviews, 4, 105-127.

FONBERG, E. (1981). Specific versus unspecific functions of the amygdala. In Y. Ben-Ari (Ed.), The amygdaloid complex (pp. 281-291). Amsterdam: Elsevier/North-Holland.

GroenewEGEN, H. J. (1988). Organization of the afferent connections of the mediodorsal thalamic nucleus in the rat, related to the mediodorsal-prefrontal topography. Neuroscience, 24, 379-431.

IsAacson, R. L. (1982). The limbic system (2nd ed.). New York: Plenum.

Kessler, J., Markowitsch, H. J., OtTo, B. (1982). Subtle but distinct impairments of rats with chemical lesions in the thalamic mediodorsal nucleus, tested in a radial arm maze. Journal of Comparative \& Physiological Psychology, 96, 712-720.

KoLB, B. (1974). Prefrontal lesions alter eating and hoarding behavior in rats. Physiology \& Behavior, 12, 507-511.

KOLB, B. (1977). Studies on the caudate-putamen and the dorsomedial thalamic nucleus of the rat: Implications for mammalian frontal-lobe functions. Physiology \& Behavior, 18, 237-244.

Kolb, B., Pittman, K., Sutherland, R. J., \& Whishaw, I. Q. (1982). Dissociation of the contributions of the prefrontal cortex and dorsomedial thalamic nucleus to spatially guided behavior in the rat. $B e$ havioral Brain Research, 6, 365-378.

Krettek, J. E., \& Price, J. L. (1977). The cortical projections of the mediodorsal nucleus and adjacent thalamic nuclei in the rat. Journal of Comparative Neurology, 171, 157-192.

LEONARD, C. M. (1969). The prefrontal cortex of the rat: I. Cortical projections of the mediodorsal nucleus: II. Efferent connections. Brain Research, 12, 321-343.

LiMA, S. L. (1985). Maximizing feeding efficiency and minimizing time exposed to predators: $A$ trade off in the black-capped chickadee. Oecologia, 66, 60-67.

LIMA, S. L., \& VLONE, T. J. (1986). Influence of predation risk on diet selection: A simple example in the grey squirrel. Animal Behavior, 34, 536-544.

Lima, S. L., VALONe, T. J., \& CARACO, T. (1985). Foraging-efficiencypredation-risk trade-off in the grey squirrel. Animal Behavior, 33, 155-165.

Markowitsch, H. J. (1982). Thalamic mediodorsal nucleus and memory: A critical evaluation of studies in animals and men. Neuroscience \& Biobehavioral Reviews, 6, 351-380.

Mogenson, G. J. (1987). Limbic-motor integration. Progress in Psychobiology \& Physiological Psychology, 12, 117-170.

Mogenson, G. J., NeILsen, M. (1984). A study of the contribution of hippocampal-accumbens-subpallidal projections to locomotor activity. Behavioral \& Neural Biology, 42, 38-51.

Mogenson, G. J., \& WU, M. (1988). Disruption of food hoarding by injections of procaine into mediodorsal thalamus, GABA into subpallidal region and haloperidol into accumbens. Brain Research Bulletin, 20, 247-251
Nieder, L., Cagnin, M., \& Parisi, V. (1982). Burrowing and feeding behavior in the rat. Animal Behavior, 30, 837-844.

O'KeEFE, J., \& Dostrovsky, J. (1971). The hippocampus as a spatial map: Preliminary evidence from unit activity in the freely-moving rat. Brain Research, 34, 171-175.

Olton, D. S., Branch, M., \& Best, P. J. (1978). Spatial correlates of hippocampal unit activity. Experimental Neurology, 58, 387-409.

Olton, D. S., Walker, J. A., GAGe, F. H. (1978). Hippocampal connections and spatial discrimination. Brain Research, 139, 295-308.

Olton, D. S., Walker, J. A., Wolf, W. A. (1982). A disconnection analysis of hippocampal function. Brain Research, 233, 241-253.

Pellegrino, L. J., Pellegrino, A. S., a Cushman, A. J. (1979). $A$ stereotaxic atlas of the rat brain (2nd ed.). New York: Plenum.

Phelps, M. T., Roberts, W. A. (1989). Central-place foraging by Rattus norvegicus on a radial maze. Joumal of Comparative Psychology, 103, 326-338.

Pyke, G. H., Pulliam, H. R., Charnov, E. L. (1977). Optimal foraging: A selective review of theory and tests. Quarterly Review of Biology, 52, 137-154

ROBERTS, W. A. (in press). Foraging by rats on a radial maze: Learning, memory, and decision rules. In I. Gormezano \& E. A. Wasserman (Eds.), Learning and memory: Behavioral and biological substrates.

Roberts, W. A., Phelps, M. T., Schacter, G. B. (in press). Stimulus control of central place foraging on the radial maze. In $W$. $K$. Honig \& J. G. Fetterman (Eds.), Cognitive aspects of stimulus control.

Rolls, E. T., \& Rolss, B. J. (1973). Altered food preferences after lesions in the basolateral region of the amygdala in the rat. Joumal of Comparative \& Physiological Psychology, 83, 248-259.

STAmm, J. S. (1953). Effects of cortical lesions on established hoarding activity in rats. Joumal of Comparative \& Physiological Psychology, 46, 299-304.

STOKEs, K. A. (1988). Memory and cue utilization in rats with mediodorsal thalamic lesions. Unpublished doctoral dissertation, University of Virginia.

STOKEs, K. A., BEST, P. J. (1988). Mediodorsal thalamic lesions impair radial maze performance in the rat. Behavioral Neuroscience, 102, 294-300.

Vander Wall, S. B., Smith, J. G. (1987). Cache-protecting behavior of food-hoarding animals. In A. C. Kamil, J. R. Krebs, \& H. R. Pulliam (Eds.), Foraging behavior (pp. 611-644). New York: Plenum.

VANDERWOLF, C. H. (1971). Limbic-diencephalic mechanisms of voluntary movement. Psychological Review, 78, 83-113.

VERGNES, M. (1981). Effect of prior familiarization with mice on elicitation of mouse-killing in rats: Role of the amygdala. In Y. Ben-Ari (Ed.), The amygdaloid complex (pp. 293-304). Amsterdam: Elsevier/North-Holland.

Waring, A. E., Means, L. W. (1976). The effect of medial thalamic lesions on emotionality, activity, and discrimination learning in the rat. Physiology \& Behavior, 17, 181-186.

Whishaw, I. Q., ODDIE, S. D. (1989). Qualitative and quantitative analyses of hoarding in medial frontal cortex rats using a new behavioral paradigm. Behavioral Brain Research, 33, 255-266.

WhishaW, I. Q., \& TOMIE, J.-A. (1989). Food-pellet size modifies the hoarding behavior of foraging rats. Psychobiology, 17, 93-101.

WolFE, J. B. (1939). An exploratory study of food-storing in rats. Journal of Comparative \& Physiological Psychology, 28, 97-108.

YANG, C. R., Mocenson, G. J. (1987). Hippocampal signal transmission to the pedunculopontine nucleus and its regulation by dopamine D2 receptors in the nucleus accumbens: An electrophysiological and behavioral study. Neuroscience, 23, 1041-1055.

(Manuscript received May 25, 1990; revision accepted for publication November 1, 1990.) 